\title{
CONTRIBUIÇÃO À PATOGENIA E TERAPEUTICA DO ACIDENTE VASCULAR CEREBRAL
}

\author{
G. Scrimert *
}

Até há 30 anos, o ponto de vista de Charcot e Bouchard sôbre a patogenia do acidente cerebral, era indiscutido; o acidente cerebral era considerado como hemorragia cerebral, por rotura de vaso, de causa hipertensiva. Loewenfeld e Pick foram os primeiros a duvidar que, na etiologia do acidente cerebral, a rotura de vasos fôsse necessária. Rosenblath (1918) interpretou o insulto cerebral não como conseqüência de um rotura de vaso, porém como lesâo cerebral circunscrita causada por agentes enzimáticos. Com êstes trabalhos, foi iniciada uma discussão que continua até hoje.

Sabemos com segurança que não podemos interpretar todos os acidentes cerebrais como conseqüência de rotura de vasos e subseqüente hemorragia. Da mesma forma, nem sempre êste acidente é conseqüência de oclusão embólica, trombótica ou arteriosclerótica. Muitas vêzes não se encontram nos vasos cerebrais, alterações anátomo-patológicas que expliquem o insulto como uma isquemia esclerosante.

Considerando as causas anátomo-patológicas do acidente cerebral, podemos distinguir três quadros diversos: o derrame, o amolecimento branco e o amolecimento vermelho. Certamente devemos considerar o derrame como conseqüência de uma rotura de vasos no sentido clássico, especialmente se houver inundação ventricular. Os amolecimentos, branco e vermelho, são considerados hoje como lesões isquêmicas da área cerebral correspondente. Ültimamente também se modificaram as opiniōes sôbre a incidência de amolecimentos e derrames cerebrais. Segundo diversas estatísticas, 80 a $90 \%$ dos acidentes cerebrais são devidos a amolecimentos e apenas os restantes são causados por derrames.

Comparando a mortalidade nos derrames e nos amolecimentos, verifica-se que os casos de derrame são pràticamente sempre fatais, e que a morte sobrevém, via de regra, durante as primeiras 48 horas. Nos casos de amolecimento. a mortalidade precoce só ocorre em 50\% dos casos, apro-

Conferência lida na Associação Paulista de Medicina, em 21 de agôsto de 1953. 'Tradução do original alemão pelo Doutorando Kurt Kloetzel.

* Professor de Clínica Médica da Universidade München (Alemanha). 
ximadamente. Devemos, entretanto, considerar que o nosso material clínico e de autópsia é constituído, principalmente, por casos graves, pois grande número de acidentes cerebrais mais benignos são tratados em casa do próprio doente e, portanto, em geral não entram nas esta!́isticas; uma estatística comparativa, mais exata, redundaria em dados de sobrevivência ainda mais favoráveis para os casos de amolecimentos cerebrais.

Quanto à etiologia do processo isquêmico, isto é, à pergunta se é causado por alterações funcionais ou anatômicas, os dados do material reunido de Popper permitem concluir que em três quintos dos casos com amolecimento vermelho ou branco, não são encontradas, na autópsia, alterações anatômicas suficientes que deponham a favor de oclusão dos vasos na região atingida. E' necessário frisar ainda que os casos com êxito letal são os que apresentam áreas de amolecimento mais extensas; se fôssem examinados todos os casos de apoplexia, incluindo os de natureza leve e passageira, como os chamados insultos angiospásticos, certamente o número de oclusões verdadeiras de vasos seria ainda menor.

Quanto à patogenia, temos duas hipóteses: de um lado a teoria clássica que invoca um derrame espontâneo, conseqüência de hipertensão arterial; neste caso, admite-se que a rotura é precedida de enfraquerimento arteriosclerótico da parede vascular (Morgagni, Aschoff, Ruehl, Wolff, Boehme, e outros). De outro lado, temos a suposição de que o acidente se dá por uma lesão tissular circunscrita, devida a isquemia, de origem em parte anatômica e em parte funcional.

Rosenblath foi o primeiro a considerar os amolecimentos como conseqüência de isquemia. Baseou seu ponto de vista nas idéias de Romberg, que considerava a hipertensão como predominantemente de origem renal, acreditando que as substâncias nefrogênicas eram a causa de lesões tissulares focais. À luz destas hipóteses, era necessário explicar uma hemorragia ulterior, como acontece nos amolecimentos vermelhos, como causada por lesão vascular secundária. A êsse respeito Schwartz acreditava que a hemorragia se processasse por diapedese, enquanto Westphal e Baer, por diérese e rexis no território dos pequenos vasos. E' de pouca importância para a interpretação das conseqüências do acidente cerebral, saber se se trata de uma lesão primária do parênquima nervoso que causa a alteração secundária dos vasos, com conseqüente hemorragia, ou se há uma lesão primária da parede vascular, por dano isquêmico, conforme acreditavam Schwartz e Spatz.

Quando se iniciava a discussão sôbre a patogenia do insulto cerebral, Gustav von Bergmann desenvolveu a patologia funcional, ressaltando a importância dos distúrbios da irrigação sangüínea para a patogenia das diversas lesões tissulares. Nessa ocasião se originou a teoria neuro-espasmogênica da úlcera gástrica, hoje universalmente aceita; também dêsse tempo datam as observaçóes fundamentais sôbre a natureza da angina de peito, encarada como conseqüente a isquemia miocárdica, de base essencial- 
mente funcional. $O$ desenvolvimento dessa hipótese funcional, foi de grande utilidade no campo do acidente vascular cerebral, pois, estendendo as idéias de von Bergmann e baseado em dados clínicos e experimentais, Westphal desenvolveu uma teoria sôbre a patogenia do acidente cerebral apoplético, colocando sempre, como causa inicial dêste fenômeno, um distúrbio funcional. Kauffmann, outro discípulo de Bergmann, criou a expressão "insulto angiospástico", interpretando as paralisias e os distúrbios de consciência passageiros dos hipertensos, ao contrário de Volhard e outros, não como fenômenos pseudo-urêmicos, mas como conseqüência de isquemia focal passageira, por angiospasmos.

Westphal via também a causa do acidente num estreitamento funcional dos vasos, propensos a espasmos em pacientes hipertensivos; dada a grande sensibilidade da substância cerebral à anoxemia, éstes espasmos podem determinar, após poucos minutos, lesões irreversíveis dos tecidos. Nos pacientes hipertensos espasmos vasculares podem ocorrer fàcilmente em territórios diversos; estímulos externos, como, por exemplo, um resfriamento repentino das mãos com água gelada, podem causar elevação rápida da pressão sangüínea. Villaret e Cachera, em cães e mediante fenestração do crânio, observaram angiospasmos dos vasos cerebrais, em diversas localizações. Exames do fundo de ôlho confirmam as consideráveis alterações do calibre dos vasos em indivíduos hipertensos.

E' verdade que a patogenia funcional do acidente vascular cerel.ral teve adversários importantes, entre os quais Aschoff. Apesar disto, podemos afirmar que quase todos os autores que se ocuparam do assunto concordam em que, ao lado de alterações anatômicas, como arterites e esclerose, também a isquemia funcional pode originar um insulto com graves repercussōes.

Argumento importante em favor da etiologia funcional angiospástica é o fato de ser o acidente cerebral muitas vêzes precedido por paralisias de pequena duração ou por passageiros distúrbios da consciência provocados por alteraçộes fugazes cuja sede é da mesma localização que o acidente definitivo que sobrevém ulteriormente; são êstes os acidentes angiospásticos de Kauffmann, ou as crises vasculares fugazes, descritas por Pal, acompanhados de crises repentinas de hipertensão arterial e de sintomas cerebrais focais de curta duração. São inúmeras as formas intermediárias entre os sintomas passageiros e reversíveis e o acidente vascular cerebral definitivo.

Não se deve, entretanto, exagerar apontando os angiospasmos como as únicas causas da isquemia cerebral, quando não sejam encontradas alterações vasculares suficientes para explicar o acidente. Estudos recentes sôbre a irrigação cerebral e as necessidades de oxigênio do cérebro, demonstram que em grande número de outras condiçōes funcionais pode ocorrer isquemia focal ou generalizada. Em recente congresso da "Deutsche Cesellschaft fuer Kreislaufforschung", Schneider, Bodechtel, Riechert e outros se pronunciaram a êste respeito, demonstrando que a irrigação cerebral é 
muito sensível em suas reações às oscilações de pressão arterial. Schneider verificou que a queda da pressão sangüínea para cêrca de 40 a $50 \mathrm{mi}$ límetros, leva a um ponto crítico, além do qual a irrigação sangüínea das células cerebrais se torna insuficiente, mesmo estando os vasos intactos; o ponto crítico da pressão sangüínea é sempre mais elevado em alterações estenosantes dos vasos. Portanto, mesmo uma queda ligeira da pressão arterial em território no qual os vasos estejam estenosados, pode determinar perigosa isquemia em certas áreas cerebrais. Isto parece ocorrer principalmente em hipertensos, porque a estrutura de seus vasos se adapta com o tempo à hipertensão; em tais circunstâncias, a brusca diminuição da pressão arterial determina aumento da resistência vascular periférica (Wiwell). Em diversas moléstias do aparêlho circulatório pode haver uma queda repentina da pressão, bem como esta pode ser desencadeada por diversas drogas, como sejam os bloqueadores do simpático, os simpatolíticos e os vasodilatadores.

Freqüentes são os acidentes vasculares cerebrais na fase de choque circulatório, no estágio agudo do enfarte do miocárdio, no qual a pressão pode cair de níveis normais ou elevados, para 90 a 100 milímetros ou ainda menos. Tais acidentes nem sempre podem ser explicados por embolias ou tromboses, mas, provàvelmente, pelo fato de pessoas que sofrem de enfartes do miocárdio, também terem uma esclerose generalizada com conseqüente estenose dos vasos cerebrais. E' assim que certos setores cerebrais enquanto a pressão arterial estiver normal ou elevada, recebem irrigação sangüínea suficiente; com a queda repentina da pressão que ocorre no enfarte do miocárdio, êsses territórios se tornam isquêmicos. Também no choque pós-operatório e traumático ou no colapso, pode haver o mesmo tipo de acidente, se houver alterações vasculares correspondentes ou se o ponto crítico da pressão arterial fôr ultrapassado. Não raramente são, assim, mascarados outros quadros clínicos, como o do enfarte do miocárdio. Bodechtel chamou a atenção para o fato de, ao lado da síndrome típica de Adams-Stokes no bloqueio atrioventricular, também outras alterações do ritmo cardíaco e, não raramente, uma grave insuficiência ventricular esquerda poderem originar isquemia cerebral, quando houver, primàriamente, uma alteração vascular. Essas isquemias podem ser irreversíveis e assumir o aspecto de um acidente vascular cerebral.

Nossas próprias observações mostraram que a queda da pressão arterial na embolía pulmonar também pode desencadear um insulto cerebral. Em dois casos foi possível demonstrar, anátomo-patològicamente, que os amolecimentos se deram em áreas de vasos prèviamente estenosados por esclerose. Também nestes casos a irrigação sangüínea era suficiente na vigência de hipertensão arterial, cuja queda levou a isquemia irreversível.

Assim, observações clínicas e anátomo-patológicas mostram que lesões isquêmicas cerebrais podem aparecer durante uma queda brusca da pressão arterial, desde que os vasos cerebrais estejam prèviamente esclerosados. 0 
reconhecimento dêste fato é de importância especial hoje em dia, pelo uso cada vez mais freqüente de hipotensores de ação acentuada e pela freqüência com que, em operações cirúrgicas, se recorre ao bloqueio completo do sistema simpático, baixando a pressão arterial para 60 a 70 milímetros; pessoas de idade avançada podem correr graves perigos nestas eventualidades, especialmente se fôrem sujeitas à hipertensão arterial.

Sem dúvida, os simpatolíticos representam grande auxílio no tratamento da hipertensão arterial e de diversos distúrbios de irrigação sangüínea. Entretanto, o emprêgo indiscriminado dessas drogas pode provocar uma queda muito brusca da pressão arterial, provocadora de lesão cerebral. Tivemos ocasião de observar um caso em que foram administradas doses excessivamente altas de simpatolíticos do grupo dos alcalóides do esporão do centeio para o tratamento de claudicação intermitente devida a arteriosclerose periférica; a pressão sistólica do paciente, já baixa, caiu de 115 para 90; cinco dias após o início do tratamento, ocorreu um acidente vascular cerebral, falecendo o paciente 8 dias depois; a autópsia não mostrou oclusão vascular mas extensa esclerose da artéria cerebral média, em cujo território se encontrou um extenso foco de amolecimento branco. Não há dúvida que se deve relacionar, nesie caso, a queda da pressão arterial com o acidente vascular cerebral.

Assim, embora atribuindo ao acidente cerebral uma etiologia funcional, devemos ter sempre em mente que as causas da isquemia cerebral podem ser diversas; espasmos vasculares, assim como a queda da pressão arterial podem causar um insulto cerebral. Devemos também considerar que causas de origem funcional só levam à isquemia cerebral irreversível quando há uma lesão primúria dos vasos e, assim, o distúrbio funcional é apenas um fator adicional. Precisamos incluir, pois, na patogenia do acidente cerebral ao lado dos angiospasmos e da diminuição funcional da irrigação sangüinea cerebral, as lesões primárias dos vasos por arteriosclerose, arterite luética, ou qualquer espessamento inflamatório da íntima dos vasos.

$O$ reconhecimento da isquemia como ponto de partida para a maioria dos casos de acidente vascular cerebral, sugere o emprêgo de todos os meios para aumentar a irrigação cerebral e as trocas gasosas das células cerebrais.

Desde muito tempo, autores francêses vêm recomendando o emprêgo de nitritos, benzoato de benzila, beladona e acetilcolina, no tratamento do acidente vascular cerebral; o mesmo sentido têm os trabalhos de Villaret e Cachera, Gilvert e De Takats, que tentaram interromper o espasmo dos vasos cerebrais com bloqueio do simpático cervical pela novocaína. A prática há anos adotada na Alemanha e em outros países, de injetar glicose em altas concentrações, não teve como motivo sòmente uma terapêutica do edema cerebral, mas visava provocar também uma vasodilatação.

Há bastante tempo se recomendava o uso de corpos purínicos sob forma de preparados com teofilina, no tratamento do acidente vascular cerebral na fase aguda. Na Alemanha, Nonnembruch foi o primeiro a ad- 
vogar o uso dêstes preparados; contudo, o emprêgo desta terapêutica não se generalizou.

Mainzer, em Alexandria, estudando a patogenia e preocupando-se com a terapêutica do acidente vascular cerebral, demonstrou a ação extremamente favorável de um preparado de corpos purínicos, a aminofilina. Trata-se de um composto preparado nos Estados Unidos da América do Norte, idêntico a um preparado alemão, o Euphyllin, que é constituído de teofilina dissolvida em etileno-diamina. Há três anos, Mainzer publicou um trabalho sôbre um grupo de casos em que a injeção precoce de aminofilina atuou eficientemente contra a perda de consciência e a paralisia em grande percentagem dos pacientes, em muitos dos quais os efeitos se fizeram sentir poucos minutos após a administração da drega. Os melhores resultados foram obtidos com doentes atendidos poucos minutos após o início do insulto. Mesmo nos casos em que várias horas tinham decorrido entre o início do acidente e o tratamento, Mainzer ainda conseguiu alguns resultados significativos. Dos resultados obtidos concluiu Mainzer que a ação espasmolítica dos corpos purínicos, aumentada pela ação vasodilatadora igualmente potente da etileno-diamina, é eficiente no combate ao angiospasmo.

Estimulados pelos resultados obtidos por Mainzer, começamos, há três anos, a tratar os casos de acidentes cerebrais com o Euphyllin. Há dois anos relatamos no congresso da "Deutsche Gesellschaft fuer Innere Medizin", as observações de 18 casos, dos quais 7 tiveram uma melhoria notável imediaiamente após injeção intravenosa de 0,12 a 0,24 g de Euphyllin; observamos, nestes últimos pacientes, como já assinalara Mainzer, melhora da perturbação da consciência e rápida regressão da paralisia. Em 3 pacientes observamos melhoras que sobrevieram mais demoradas, não imediatamente após a administração da droga.

Desde então o número de nossos casos aumentou consideràvelmente. Dispomos agora de 32 casos de acidentes vasculares cerebrais, dos quais 15 tratados com Euphyllin imediatamente após o início do insulto. Dêstes 15 casos, 12 reagiram imediatamente à injeção intravenosa do preparado; dos casos restantes, muitos dos quais atendidos diversas horas, ou mesmo dias após o início do acidente, aproximadamente metade apresentou reação favorável. Nos doentes tratados dentro das primeiras 24 horas após o icto, foram observadas melhoras da paralisia, dos distúrbios da linguagem e, ocasionalmente, dos distúrbios da consciência; nestes casos, entretanto, a melhoria não foi tão acentuada como nos casos em que o tratamento foi instituído nas primeiras duas a três horas. A tendência à melhora diminui com o decorrer do tempo. Nos casos em que o acidente se dera há mais de um dia, pràticamente não houve sucesso. Portanto, para ser útil. êste tipo de tratamento deve ser instalado o mais precocemente possível. 
Para ilustrar, resumimos três observações:

Caso 1 - Homem com 80 anos de idade que vínhamos tratando de angina pectoris grave, queixou-se, certa manhã, de violenta cefaléia unilateral e sensação de obnubilação. Procurou-nos acompanhado de seu filho, sentindo-se já que a tala do paciente se tornava confusa e que se instalava ptose da comissura labial direita. Ao ingressar no hospital o paciente perdeu os sentidos. Injetamos c,12 de Euphyllin por via intravenosa, aproximadamente 8 a 10 minutos após início do acidente vascular cerebral. Durante a injeção a obnubilação começou a diminuir, voltando a íala; poucos minutos depois desapareceu a hemiplegia. No mesmo dia, decorridas poucas horas, o paciente teve um insulto idêntico ao primeiro. 'l'ambém desta vez tivemos a possibilidade de administrar a droga poucos minutos após o início do insulto. As paralisias que se iniciavam e os distúrbios da fala regrediram. $O$ paciente não mais teve acidentes cerebrais, vindo mais turde a falecer em conséquiência de um enfarte do miocárdio.

Caso 2 - Paciente de 82 anos acordou repentinamente durante a noite, demonstrando inquietação. Os parentes notaram que êle estava completamente contuso, não podendo falar e apresentando início de uma hemiplegia esquerda; lugo a seguir perdeu completamente os sentidos. Aproximadamente uma hora após o início do acidente, injetamos por via intravenosa, 0,24 $\mathrm{g}$ de Euphyllin. Durante a injeção o paciente pôs-se a falar, a paresia facial, antes bem aparente, desapareceu. Meia hora depois o doente estava quase completamente consciente, com leves distúrbios motores. Uma segunda injeção de $0,12 \mathrm{~g}$ de Euphyllin, admınistrada após uma hora, melhorou ainda mais o estado do paciente. No decorrer de alguns dias a paralisia regrediu completamente. Em duas ocasiões o paciente apresentou sinais iniciais de acidente vascular cerebral que puderam ser controlados por injeções intravenosas de Euphyllin.

Caso 3 - Mulher com 52 anos de idade, que sofrera de hipertensão arterial há anos (rim atrótico, esclerose maligna), perdeu os sentidos repentinamente. Decorridos poucos minutos, deu entrada em nossa clínica, onde estava sendo observada. Após uma injeção intravenosa de 0,24, g de Euphyllin voltou à consciência, em poucos minutos, ficando com hemiparesia esquerda, que regrediu nos dias subseqüentes com a continuação do tratamento com Euphyllin; também regrediu aos poucos a afasia motora.

Poderia citar aqui mais casos neste gênero, que tiveram curso semelhante, quando os pacientes foram tratados com Enphyllin no decorrer das primeiras duas a três horas, ou melhor ainda, poucos minutos após o início do acidente. Além disto, numerosas comunicações de colegas que empregaram a mesma terapêutica, confirmaram os mesmos resultados.

Infelizmente o número de nossos casos é reduzido. Isto se explica pelo fato de a maioria dos acidentes vasculares cerebrais se apresentar na clínica hospitalar muitas horas, ou mesmo dias, após o início do insulto, quando esta terapêutica é inútil. A terapêtica do acidente cerebral com Euphyllin é a terapêtica do médico prático, que é o primeiro a ser chamado. Atrasos de horas, ou mesmo de minutos, podem favorecer o estabelecimento de lesões cerebrais irreversíveis; de minuto em minute diminuem as esperanças de sucesso terapêutico. 


\begin{tabular}{|c|c|c|c|c|}
\hline G $\quad r \quad$ u $p$ & 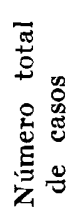 & 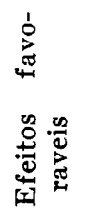 & 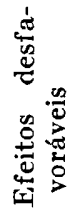 & 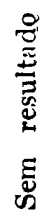 \\
\hline $\begin{array}{l}1 \text { - 'I'ratamento começado dentro de } 2 \text { a } \\
3 \text { horas após o princípio do insulto } \\
\text { apoplético } \ldots \ldots \ldots \ldots \ldots \ldots \ldots \ldots \ldots \ldots\end{array}$ & 15 & 12 & 1 & 2 \\
\hline $\begin{array}{r}2 \text { - 'Tratamento começado entre } 3 \text { e } 24 \\
\text { horas após o princípio do insulto apo- } \\
\text { plético } \ldots \ldots \ldots \ldots \ldots \ldots \ldots \ldots \ldots \ldots \ldots\end{array}$ & 11 & $6^{*}$ & 1 & 4 \\
\hline $\begin{array}{l}3 \text { - 'Tratamento começado passadas mais } \\
\text { de } 24 \text { horas do princípio do insulto } \\
\text { apoplético } \ldots \ldots \ldots \ldots \ldots \ldots \ldots \ldots \ldots \ldots \ldots \ldots \ldots \ldots\end{array}$ & 6 & $1 * *$ & 0 & 5 \\
\hline Número total de casos $\ldots \ldots \ldots$ & 32 & 19 & 2 & 11 \\
\hline
\end{tabular}

'labela 1 - Resultados da terapêutica intravenosa com Euphyllin na apoplexia. * Dos 6 casos com resultados favoráveis reunidos no grupo 2, em 4 as melhoras toram nítidas, ao passo que em 2 os resultados foram incertos. ** Neste caso do grupo 3 em efeitos favoráveis o resultado foi incerto.

Os resultados de nossas observações estão resumidos na tabela 1 , na qual foram comparados os casos que foram tratados no decorrer das primeiras horas, com aquêles em que o acidente se dera há mais tempo. Pode ser verificado que a possibilidade de sucesso diminui ràpidamente com o decorrer do tempo entre o início do insulto e a primeira administração de Euphyllin. Nos casos em que o preparado foi administrado nas primeiras duas a três horas (grupo 1), mais de $80 \%$ dos pacientes reagiram favoràvelmente $\mathrm{e}$, em parte, restabeleceram-se por completo. Já no grupo 2, compreendendo casos em que a injeção de Euphyllin foi feita entre 3 e 24 horas após o início do acidente, os sucessos foram menores. No grupo 3 , compreendendo pacientes tratados 24 ou mais horas após o início do acidente, pràticamente não houve mais resultados favoráveis a registrar. Decorridas 24 horas, não contamos com o restabelecimento de áreas isquêmicas, podendo esperar apenas uma melhora na circulação colateral, o que favorece o restabelecimento da função cerebral e, até certo ponto, impede novos espasmos arteriais.

O emprêgo de um espasmolítico ativo que, segundo nossos conhecimentos atuais, deve aumentar a irrigação cerebral, motivou dúvida quanto à sua aplicação em casos de rotura vascular primária, quando estaria contraindicado, pois é lógico supor que, em tais circunstâncias, a hemorragia aumentaria. A esta objeção só podemos responder considerando que nestes derrames o óbito ocorre na maioria dos casos, tratados ou não; êstes casos representam, no máximo, a quinta parte do total dos acidentes cere- 
brais. Ao contrário dêstes, temos os casos nos quais o acidente se inicia com isquemia, em parte de origem funcional; se administrarmos uma terapêutica com corpos purínicos, proporcionaremos oportunidade para o restabelecimento de suas funções físicas e mentais. Infelizmente não temos a possibilidade de distinguir, num insulto cerebral agudo, entre o aridente de origem isquêmica $e$ o derrame. Acreditamos, porém, que temos o direito de assumir a responsabilidade, como numa intervenção cirúrgica, de prejudicar eventualmente um pequeno grupo, já sem esperanças, a fim de ajudar a um grupo maior e mais importante. E' necessário frisar aizda que, em apenas dois casos que mais tarde verificamos serem de derrsme, tivemos a impressão que o quadro piorou após a terapêutica pelo Euphyllin. Na maioria dos casos, a queda da pressão arterial concomitante à vasodilatação, provàvelmente evita o agravamento da hemorragia. E é por isto que o Euphyllin deve ser preferido, pois a queda de pressão arterial que se verifica com a sua administração é muitas vêzes considerável.

Os acidentes vasculares cerebrais de origem embólica seguramente se beneficiam com essa terapêutica. A experiência do passado demonstra que vasodilatadores também podem ser empregados com sucesso em embolias cerebrais, como por exemplo na endocardite crônica ou em casos de lesões valvulares. Já tivemos ocasião de observar sucessos com o emprêgo de Euphyllin, assim como de Eupaverin em casos desta natureza. A interpretação dêstes sucessos se baseia nos espasmos reflexos que ocorrem no território dos vasos colaterais, após a embolia, conforme verificaram Villaret e Cachera. Mainzer mencionou a existência de espasmos nos vasos colaterais em enfartes do miocárdio por embolia ou trombose, espasmos cujo desaparecimento logo após o emprêgo de vasodilatadores pode diminuir a extensão do enfarte. 0 mesmo pesquisador admite que fenômenos semelhantes ocorrem nos vasos cerebrais.

O mecanismo farmacológico provável da ação dos preparados de leofilina tem sido muito discutido ùltimamente porque têm sido registrados resultados contraditórios sôbre a ação dêstes preparados na irrigação sangüínea do cérebro. Segundo os trabalhos de Noell e de Schneider, o fluxo sangüíneo na artéria carótida interna, medido pelo relógio térmico de Rein, aumenta consideràvelmente após a administração intravenosa de teofilina, assim como de etileno-diamina; a irrigação cerebral aumenta a despeito da simultânea baixa na pressão arterial. Os mesmos resultados forám por nós obtidos em vasos cerebrais em estado de espasmo; investigamos a irrigação da artéria vertebral no cão, utilizando igualmente um relógio térmico de Rein para o registro do fluxo sangüíneo. A fim de reproduzir os espasmos, fator de importância no desenrolar da apoplexia, utilizamos a ação vasoconstritora de extratos de hipófise ou de cloreto de bário.

A figura 1 mostra a ação de $0,24 \mathrm{~g}$ de Euphyllin sôbre o fluxo sangüíneo na artéria cerebral, prèviamente constrita pela aplicação de 9 unidades de extrato de lobo posterior de hipófise; apesar da queda de pressão sangüínea, o fluxo voltou ao seu antigo valor com a injeção intravenosa 

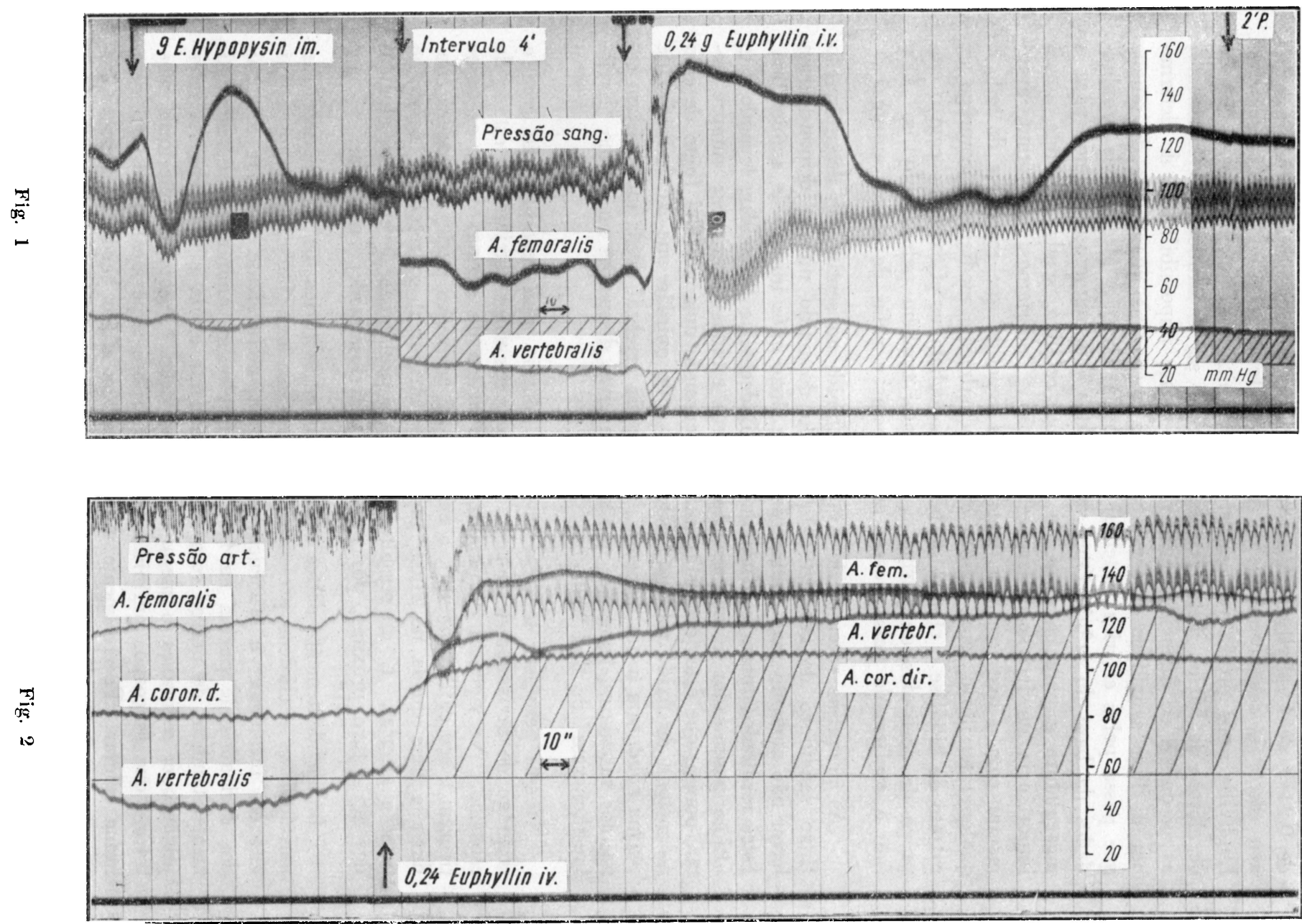

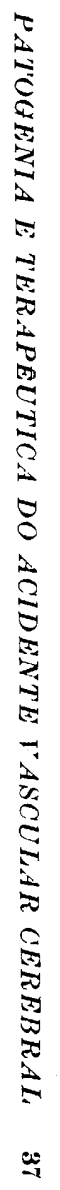


de $0,24 \mathrm{~g}$ de Euphyllin. A figura 2 mostra o aumento do fluxo sangüíneo cerebral, das coronárias e da artéria femural com administração de Euphylliní após prévia vasoconstrição determinada pelo emprêgo de $50 \mathrm{mg}$ de cloreto de bário. Estes resultados devem ser encarados criteriosamente; as pesquisas de Schneider mostraram a quase impossibilidade de determinar o fluxo sangüíneo cerebral baseados apenas na quantidade de sangue que passa pelas artérias vertebral e carótida interna. Mesmo nas proximidades da base do crânio êstes vasos ainda dão numerosos ramos para a musculatura e para os ossos do segmento cefálico, sendo diminuta a sua importância na irrigação cerebral do cão. Poderíamos, entretanto, argumentar com o que tem sido tantas vêzes repetido que espasmos de todo e qualquer território reproduzidos experimentalmente mediante o emprêgo de extrato de hipófise e cloreto de bário, são debelados eficazmente com o emprêgo de derivados da purina e, portanto, também pelo Euphyllin. Êste fato é confirmado pelas nossas experiências e pelas de outros autores.

As pesquisas recentes de Kety e Schmidt no sentido de determinar o fluxo sangüíneo do cérebro pelo método do óxido nitroso demonstraram haver não aumento mas diminuição dêsse fluxo após injeção de aminofilina. Ê.stes resultados foram confirmados por Bodechtel e Schneider, levando êste último pesquisador a uma revisão de seus estudos anteriores; cumpre notar, porém, que êstes cientistas estão procurando uma possível fonte de êrro no método do óxido nitroso. Schneider é de opinião que os derivados de purina conduzam a um aumento da irrigação cerebral desde que existam espasmos vasculares, tema êste que suscitou vivas discussões no último "Kreislausfkongress" de Bad Nauheim.

Nossas pesquisas também levam a admitir uma vasodilatação com o emprêgo de derivados da purina, desde que os vasos estejam em estado de espasmo. Na vigência de uma irrigação acima do normal ou se os vasos tiverem o seu calibre natural, o emprêgo de derivados purínicos poderá conduzir a uma queda no fluxo sangüíneo, atribuivel sobretudo à baixa na pressão arterial. E' de ressaltar que êstes problemas deverão ser elucidados em futuro próximo, por pesquisas criteriosamente conduzidas.

Independentemente dêstes resultados contraditórios, os fisiologistas, farmacologistas e clínicos presentes ao congresso em Nauheim, foram unánimes em reconhecer a eficiência terapêutica, no acidente vascular cerebral, dos derivados de purina na forma de Euphyllin, aminofilina e, eventualmente, também de outros compostos. Sòmente ainda não é possível interpretar com segurança o mecanismo desta ação. Pesquisas anteriores mostraram que os corpos purínicos têm ação sôbre a permeabilidade da membrana celular. Possivelmente, haverá também efeito benéfico sôbre as trocas de oxigênio. A resposta definitiva será eventualmente dada nãc através de uma melhora na irrigação sangüínea, mas por fenômenos situados no campo do metabolismo celular. 
Sòmente pudemos indicar em linhas gerais o estado atual de nossos conhecimentos com relação ao mecanismo de ação dos corpos purínicos na apoplexia, sem nos aventurarmos a um pronunciamento definitivo. Tivemos em mira apenas apontar os resultados clínicos favoráveis que repetidas vêzes temos observado. Êstes são verificados quando o Euphyllin é empregado o mais precocemente possível, após o início do insulto cerebral; são injetadas de 0,12 a 0,24 g de Euphyllin puro ou misturado com solução glicosada a 20 ou $40 \%$, por via intravenosa, lentamente, no decurso de um a dois minutos; repete-se a injeção depois de uma a duas horas. Durante o primeiro dia, repete-se a dose três a quatro vêzes, especialmente se tiver sido verificado algum sucesso terapêutico. No geral dos casos prosseguimos com esta terapêtica por mais 10 a 14 dias, iniciando com 3 aplicações ao dia e terminando com 2 aplicações nas 24 horas. Havendo qualquer dificuldade com relação à injeção intravenosa, poder-se-á administrar por via intramuscular 0,24 a $0,48 \mathrm{~g}$ de Euphyllin; com esta via não se observam resultados tão nítidos. Talvez a diferença consista na necessidade de obter uma vasodilatação brusca e imediata no combate ao espasmo vascular.

Ainda nos mantemos fiéis à hipótese de uma ação espasmolítica dos corpos purínicos, a despeito dos resultados controvertidos dados pelo método do óxido nitroso. Apesar de haver diminuição na irrigação global do cérebro, não achamos impossível haver melhoria nas condições de circulação em áreas isquêmicas. Não raro observamos semelhantes diferenças de comportamento em outras zonas vasculares.

Mais uma vez julgamos de utilidade repetir que esta terapêtica encontra sua razão de ser tão sòmente durante as primeiras horas após o início do acidente cerebrai. Passadas 24 ou mais horas é duvidoso ao extremo haver resposta útil. Êste tipo de terapêutica deve, portanto, se tornar comum aos médicos práticos.

RESUMO

O autor descreve, de início, o mecanismo etiolóíico do acidente vascular cerebral. A grande maioria dêstes acidentes não tem como fundamento um derrame maciço provocado por rotura vascular, mas uma isquemia de territórios circunscritos, isquemia esta causada por espasmos vasculares ou por excessiva queda de pressão arterial em vasos esclerosados. O prognóstico nos casos de isquemia é melhor, pois, na maior parte dos. derrames maciços, a evolução é fatal nas primeiras 48 horas. A terapêutica de urgência visa restabelecer uma circulação adequada nas zonas isquêmicas o mais rápido possível, seja por melhora da circulação, seja por melhora mediante ativação das trocas de oxigênio.

Baseado em uma série de casos clínicos, o autor mostrou ser de grande valor terapêutico a administração intravenosa de 0,12 a $0,24 \mathrm{~g}$ de Eu- 
phyllin nos primeiros minutos ou horas após o insulto cerebral, fazendo regredir ràpidamente as paralisias e os distúrbios de consciência. Em alguns casos êste efeito já se fêz sentir durante a injeção ou logo depois, particularmente quando o medicamento é injetado menos de duas a três horas após o início do quadro clínico.

Não está devidamente esclarecido o mecanismo de ação dos preparados purínicos nos casos de acidente vascular cerebral. As pesquisas do autor mostraram haver vasodilatação com Euphyllin em vasos constritos sob a ação de cloreto de bário ou do extrato de hipófise posterior.

$\mathrm{Na}$ opinião do autor esta é a terapêutica de escolha no tratamento precoce do acidente cerebral.

11 Medizinische Universitäts,Klinik - Ziemssenstrasse 1 - München 15 Deutschland. 